\title{
EVIDENCE FOR A NEUROTRANSMITTER ROLE FOR 5-HYDROXYTRYPTAMINE IN CHICK RETINA ${ }^{1}$
}

\author{
DAVID PARKINSON AND ROBERT R. RANDO ${ }^{2}$
}

Department of Pharmacology, Harvard Medical School, Boston, Massachusetts 02115

\begin{abstract}
Evidence to support a neurotransmitter role for 5-hydroxytryptamine in chick retina is presented. Putative 5-hydroxytryptophan and 5-hydroxytryptamine extracted from chick retina have been characterized chromatographically and electrochemically and have been found to behave like the authentic compounds. Retinal tryptophan hydroxylase activity could not be demonstrated in vitro, but chick retina was able to synthesize $5-\left[{ }^{3} \mathrm{H}\right]$ hydroxytryptamine from $\left[{ }^{3} \mathrm{H}\right]$ tryptophan in vivo. Retinal 5-hydroxytryptamine levels were reduced by local injection of $\alpha$-fluoromethyldopa, an inhibitor of aromatic L-amino acid decarboxylase, or reserpine, indicating that this amine is both synthesized and stored in this tissue. The retinae of light-adapted chicks have higher levels of 5hydroxytryptamine and its major metabolite, 5-hydroxyindoleacetic acid, than dark-adapted animals. The turnover of 5-hydroxytryptamine appears to be greater in the light after inhibition of synthesis. Conversely, the rate of synthesis of 5-hydroxytryptamine appears to be greater in the dark. The possible interaction of dopaminergic neurons and the 5-hydroxytryptamine-containing cells and the effect of $\alpha$-fluoromethyldopa on this relationship are discussed.

The data lend support to the notion that 5-hydroxytryptamine in chick retina may have a neurotransmitter function.
\end{abstract}

Much evidence has been accumulated to indicate that the biogenic amines, norepinephrine, dopamine, and 5hydroxytryptamine $(5-\mathrm{HT}),{ }^{3}$ may be the neurotransmitters for some neurons in the central nervous system. In the vertebrate retina, dopamine has been identified as the possible transmitter for a class of amacrine cells with cell bodies in the inner nuclear layer (Ehinger, 1976). Sufficient 5-HT to justify a possible neuronal role for this amine has been measured only in chick (Suzuki et al., 1975) and bovine retina (Thomas and Redburn, 1979). From the use of the Falck-Hillarp histochemical fluores-

\footnotetext{
${ }^{1}$ This work was supported by United States Public Health Service Research Grant EY 70324. D. P. thanks the Wellcome Trust for a travel grant. ( $S$ )- $\alpha$-Fluoromethyldopa was a gift from Dr. J. Kollonitsch of Merck, Sharp and Dohme Research Laboratories.

${ }^{2}$ To whom correspondence should be addressed at Department of Pharmacology, Harvard Medical School, 250 Longwood Avenue, Buston, MA 02115.

${ }^{3}$ The abbreviations used are: L-AAAD, aromatic L-amino acid decarboxylase; C5-IP, pentane sulfonic acid sodium salt; C7-IP, heptane sulfonic acid sodium salt; C8-IP, octane sulfonic acid sodium salt; DOPA, dihydroxyphenylalanine; DOPAC, dihydroxyphenylacetic acid; EDTA, ethylenediaminetetra-acetate; $\alpha$-FMD, $(S)$ - $\alpha$-fluoromethyldopa; GABA, $\gamma$-aminobutyric acid; 5-HIAA, 5-hydroxyindoleacetic acid; HPLC-ECD, high pressure liquid chromatography with electrochemical detection; 5-HT, 5-hydroxytryptamine; 5-HTP, 5-hydroxytryptophan; i.p., intraperitoneally; i.vit. intravitreally; MAO, monoamine ox idase; $R_{t}$, retention time.
}

cence technique, the indoleamine of embryonic chick retina has been located in a type of amacrine cell (Hauschild and Laties, 1973) although Haggendal and Malmfors (1965) could not locate such neurons in rabbit retina. Cells capable of accumulating exogenous indoleamine amine have been identified in the retinae of many species, but these cells can only be visualized histochemically after taking up exogenous indoleamine (Ehinger and Floren, 1978; Floren, 1979a). This led Floren and Hansson (1980) to suggest that the natural transmitter of these cells was not 5 -HT but some indoleamine which was not susceptible to the histochemical fluorescence reaction.

We have been interested in the application of highly specific mechanism-based enzyme inactivators (Rando, 1974) to study neurotransmitter function in the retina. One of these inactivators, $(S)$ - $\alpha$-fluoromethyldopa $(\alpha-$ FMD), is a potent inactivator of aromatic L-amino acid decarboxylase (L-AAAD) (Kollonitsch et al., 1978). Since this enzyme is common to the synthetic routes of both dopamine and 5-HT (McGeer and McGeer, 1973a), $\alpha$ FMD should block their biosynthesis. Therefore, we have used this and other techniques to investigate whether the indoleamine in chick retina possesses any of the attributes of a neurotransmitter.

\section{Materials and Methods}

Chicks (white Leghorn, 12 days old) were obtained from Spafas, Inc., Norwich, CT and adapted to normal 
fluorescent room light for at least $16 \mathrm{hr}$ before use. For experiments involving dark-adapted animals, the chicks were kept in total darkness for $48 \mathrm{hr}$. Drugs were administered intravitreally (i.vit.) under ether anesthesia by injecting $10 \mu \mathrm{l}$ of drug solution in $0.9 \%$ saline (sterilized by filtration) into the posterior chamber of the eye. Reserpine solution for injection was prepared by dissolving $2 \mathrm{mg}$ of reserpine in $250 \mu \mathrm{l}$ of $4 \mathrm{M}$ acetic acid, diluting to the required concentration for injection, and then adjusting to about $\mathrm{pH} 4.5$ with $\mathrm{NaOH}$.

Retinae were dissected as follows: after decapitation, the eyes were removed; the front portion of the eye, including iris and lens, was removed with a razor blade; and the vitreous humor was taken out with forceps. Under a dissecting microscope, the posterior eyecup was cut in half and the two half-retinae were teased out with a flat ended spatula, taking care to minimize the amount of pigment adhering to the retina. The tissue was stored in preweighed $1.5-\mathrm{ml}$ microcentrifuge tubes at $-70^{\circ} \mathrm{C}$ until required. In experiments involving dark-adapted animals, the eyes were removed under photographic safe light illumination and cooled on ice in the dark for 5 min before dissection in an attempt to minimize any effects of the illumination necessary for dissection. Control lightadapted retinae were removed under the same conditions in this instance.

Dopamine, 5-HT, and their amino acid precursors were extracted from retinae by the method of Ponzio and Jonsson (1979) modified as follows. Retinal portions were sonicated in $100 \mu \mathrm{l}$ of cold acidified butanol $(0.85 \mathrm{ml}$ of $37 \% \mathrm{HCl} /$ liter of 1 -butanol) to which had been added 3 ng of dihydroxybenzylamine as the internal standard. The homogenate was centrifuged at $27,000 \times g$ for 30 min. The supernatant was added to $100 \mu \mathrm{l}$ of $50 \mathrm{~mm}$ sodium phosphate, $\mathrm{pH} 3.5$ (since indoleamines are more stable at less acid pH; Shellenberger and Gordon, 1971), containing $0.1 \mathrm{mM}$ sodium EDTA and $200 \mu \mathrm{l}$ of $n$-heptane. The tubes were shaken by hand for $5 \mathrm{~min}$ and centrifuged, and the organic layer was aspirated. The aqueous layer was washed with $500 \mu \mathrm{l}$ of peroxide-free ether (Udenfriend et al., 1955) by shaking for 5 min and centrifuged, and the organic layer was aspirated. Usually, 30 $\mu l$ of the aqueous solution was injected into the liquid chromatograph for analysis by reverse phase ion pair high pressure liquid chromatography with electrochemical detection (HPLC-ECD). Known amounts of dihydroxyphenylalanine (DOPA), dopamine, 5-hydroxytryptophan (5-HTP), and 5-HT were carried through the procedure to determine extraction efficiency. Absolute amounts of each compound were calculated from the peak heights with reference to the internal standard response. The retinal content of 5-hydroxyindoleacetic acid (5-HIAA) was determined by the method of Hefti (1979) after homogenizing one retina in $200 \mu \mathrm{l}$ of $0.1 \mathrm{M}$ perchloric acid, extracting with peroxide-free ether, and backwashing the organic phase with $0.1 \mathrm{M}$ sodium phosphate, pII 6.5. The ether was removed by evaporation to maximize recovery.

The liquid chromatograph consisted of a Waters M6000A pump, pulse dampner, UK6 injector, a 3-cm RP18 guard column (Brownlee), and a $\mu$ Bondapak $\mathrm{C}_{18}$ (30 $\times 4 \mathrm{~cm}$ ) reverse phase analytical column. The compounds of interest were separated by reverse phase ion pair chromatography under a variety of conditions. Generally, to measure dopamine and 5-HT in the same sample, the buffer consisted of $50 \mathrm{~mm}$ sodium phosphate, $\mathrm{pH} 3.5,7 \%$ (v/v) methanol, $0.1 \mathrm{~mm} \mathrm{Na} \mathrm{NDTA}_{2}$, and $0.1 \mathrm{gm} / \mathrm{liter}$ of sodium heptane sulfonic acid (C7-IP) as an ion pair and was pumped at $1.3 \mathrm{ml} / \mathrm{min}$. To measure 5 - $\mathrm{HT}$ alone, 0.1 $\mathrm{gm}$ /liter of sodium pentane sulfonic acid (C5-IP) was used as an ion pair and, for 5-HIAA, the $\mathrm{pH}$ also was increased to 4.0. The retention times of each compound under the various conditions are shown in 'lable I. 'The separated compounds were measured by electrochemical detection with an LC-3 amperometric detector (BAS., Lafayette) connected to a TL-3 thin layer cell packed with carbon paste (silicone grease base). The working electrode was operated at $0.60 \mathrm{~V}$ with respect to the $\mathrm{Ag}$ / $\mathrm{AgCl}$ reference electrode. The sensitivity of the technique for a particular oxidizable compound, as measured by a peak height of 5 times above base line noise, varied with the chromatographic conditions (i.e., longer retention times gave smaller peaks) but was of the order of $25 \mathrm{pg}$ for catechols and $50 \mathrm{pg}$ for hydroxyindoles per injection. The efficiency of extraction from tissues was 70 to $80 \%$ for the amines and their amino acid precursors and 30 to $35 \%$ for 5 -HIAA.

In experiments designed to measure the synthesis of 5$\left[{ }^{3} \mathrm{H}\right] \mathrm{HT}$ after an intravitreal injection of $\left[{ }^{3} \mathrm{H}\right]$ tryptophan, the retinae were dissected and extracted as above after addition of $1 \mu \mathrm{g}$ each of 5-HTP, 5-HIAA, 5-HT, and tryptophan as carriers. Then, all of the $50 \mathrm{~mm}$ phosphate, $\mathrm{pH} 3.0$, extract $(100 \mu \mathrm{l})$ was injected onto the chromatograph (buffer, $\mathrm{pH} 3.0, \mathrm{C} 7-\mathrm{IP}, 7 \%$ methanol; $1.3 \mathrm{ml} / \mathrm{min}$ ) and fractions of the column effluent were collected for liquid scintillation counting after the addition of Aquasol.

Aromatic L-amino acid decarboxylase (L-AAAD) activity was measured by a modification of the method of Laduron and Belpaire (1968) but with a final assay volume of $0.2 \mathrm{ml}$. After incubation of aliquots of the pooled high speed supernatants $(27,000 \times g$ for $30 \mathrm{~min})$ from six chick retinae (sonicated in $5 \mathrm{~mm}$ phosphate buffer, $\mathrm{pH}$ 7.0 , containing $10 \mathrm{~mm} 2$-mercaptoethanol) with $0.5 \mathrm{mM}$ L-DOPA or 5-HTP, the amines were extracted into acidwashed butanol and back-extracted into $0.1 \mathrm{M}$ phosphate, $\mathrm{pH} 3.0$, in the presence of heptane. Dopamine and 5-HT were measured by HPLC-ECD as above. This method extracts very little DOPA, but significant amounts of 5-HTP were carried through the procedure. However, 5-HTP and 5-HT were well separated by the HPLC system so that this did not pose a problem.

\section{Results}

Identification of indoleamines in chick retina. There is some doubt as to whether the indoleamine in chick retina is, in fact, 5-HT. To confirm that the compounds being extracted from chick retina were 5-HTP and 5-HT, several chromatographic and electrochemical tests were performed and compared with the response of the authentic materials. Chicks were pretreated with $\alpha$-FMD to increase levels of 5-HTP (vide infra).

Figure 1 shows a chromatogram of a co-elution experiment. The sample injected at $A$ contained $200 \mathrm{pg}$ each of 5 -Н'ГP $\left(R_{t}, 7.5 \mathrm{~min}\right.$; peak 1$)$ and 5 -HT $\left(R_{t}, 15 \mathrm{~min}\right.$; 


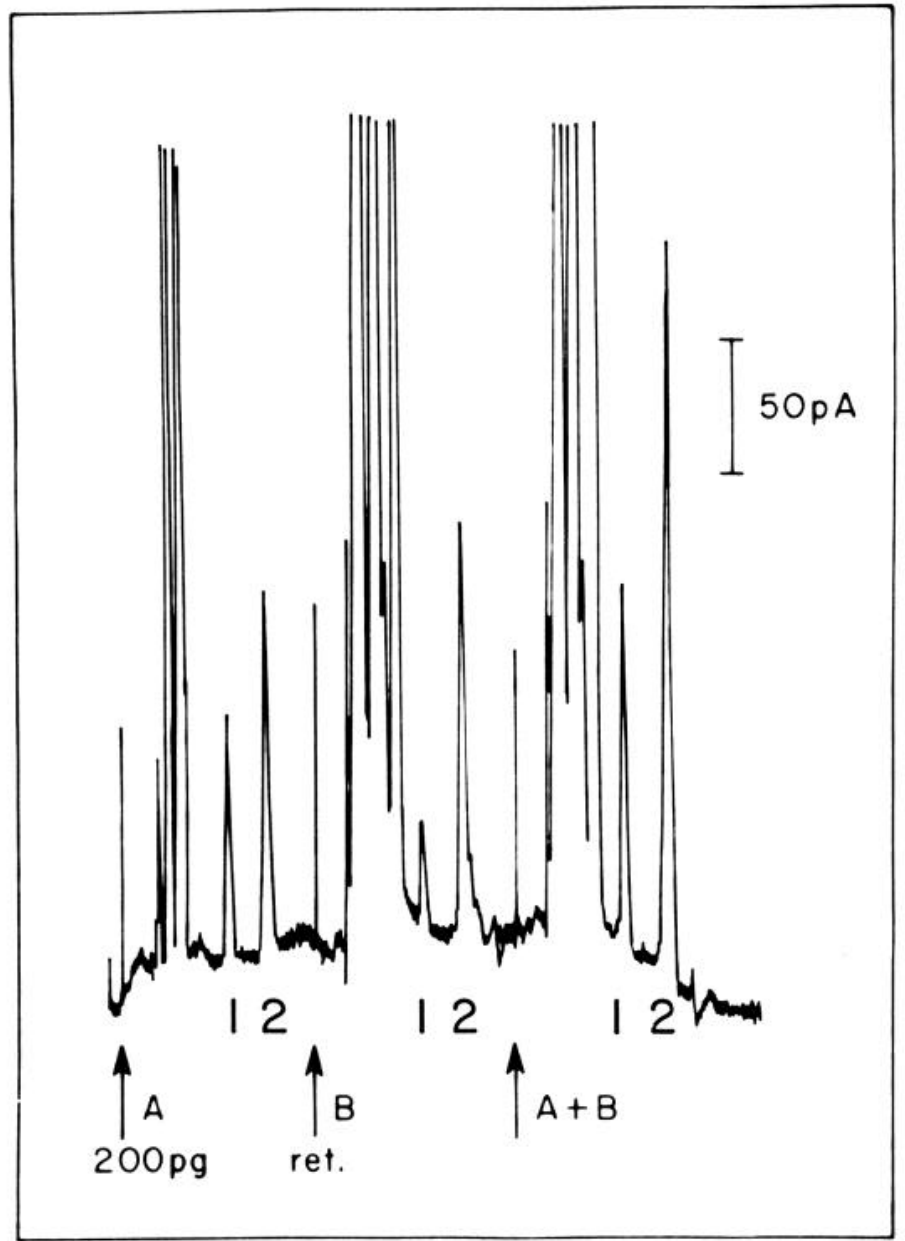

Figure 1. Co-chromatography of 5-HTP ( peak 1) and 5-HT ( peak 2) extracted from chick retina with the authentic compounds. ret., Injection of pooled extract of retinae from animals treated with $\alpha$-FMD. See text for details.

peak 2). At $B$, a portion of a pooled extract of retinae from animals treated with $\alpha$-FMD was injected. The third injection contained the same amounts as $A$ and $B$ together. It can be seen that the two materials present in chick retina co-elute with the authentic compounds and, furthermore, the peak heights of the third injection are the sum of the peaks from $A$ and $B$.

During the course of this work, two different $\mu$ Bondapak $\mathrm{C}_{18}$ columns were used and the chromatographic conditions were varied with respect to flow rate, $\mathrm{pH}$, methanol content, and ion pair (Table I). Under each of these varying conditions, the 5-HT-like material from chick retina had the same retention time as the authentic compound.

The voltammograms obtained by repetitive injection of the same sample of retinal extract and authentic compounds while varying the electrode voltage at the detector are shown in Figure 2. The profiles for authentic 5 -HTP and 5-HT are readily distinguishable, with the response to 5-HT being better maintained at lower voltages. Putative 5-HTP and 5-HT from chick retina had profiles which superimposed upon those of the authentic compounds. The voltammogram for dopamine is included for comparison.
The retinal content of putative 5 -HT in 12-day-old chicks was easily measured by HPLC-ECD, with a single injection (equivalent to about one-sixth of a retina) giving a peak height response at the appropriate time for 5-HT 20 - to 30 -fold greater than the base line noise. The retinal dopamine content of different batches of light-adapted animals was relatively constant at around $100 \mathrm{ng} / \mathrm{gm}$, wet weight. The 5-HT levels varied between batches of animals from 100 to $200 \mathrm{ng} / \mathrm{gm}$, wet weight, although they were consistent within a particular batch. Basal levels of 5-HTP approached the limit of detection of the assay.

Effects of several different drug treatments on the levels of 5-HTP and 5-HT in light-adapted chick retina. The effects of pargyline, reserpine, and $\alpha$-FMD on retinal 5-HTP and 5-HT levels are shown in Figure 3. Data for the effects on DOPA and dopamine levels also are included for comparison. Control levels of 5-HT in this group of animals were about 2 -fold greater than dopamine. Irreversible inhibition of monoamine oxidase

TABLE I

Retention times of 5-HT, dopamine, and some of their metabolites under various chromatographic conditions

The buffer consisted of $50 \mathrm{~mm}$ sodium phosphate ( $\mathrm{pH}$ as indicated), $7 \%(\mathrm{v} / \mathrm{v})$ methanol, and $0.1 \mathrm{~mm} \mathrm{Na}{ }_{2}$ EDTA pumped at $1.3 \mathrm{ml} / \mathrm{min}$.

\begin{tabular}{lccc}
\hline \multirow{2}{*}{ Amines } & \multicolumn{3}{c}{ Ion Pair Alkyl Chain Length (pH 3.5) } \\
\cline { 2 - 4 } & \multicolumn{1}{c}{$\mathrm{C} 5$} & $\mathrm{C} 7$ & $\mathrm{C} 8$ \\
\hline DHBA & 4.0 & 6.5 & 8.0 \\
Dopamine & 5.0 & 9.5 & 12.0 \\
5-HT & 12.0 & 27.5 & 41.0 \\
\hline & \multicolumn{3}{c}{ C5 Ion Pair } \\
\cline { 2 - 4 } & $\mathrm{pH} \mathrm{3.0}$ & $\mathrm{pH} 3.5$ & $\mathrm{pH} 4.0$ \\
\hline DOPA & 8.0 & 4.0 & $\mathrm{SF}^{a}$ \\
DOPAC & 25.0 & 14.5 & 10.5 \\
5-HTP & 16.0 & 8.5 & \\
5-HIAA & & 32.0 & 25.5 \\
\hline
\end{tabular}

${ }^{a}$ S.F., solvent front.

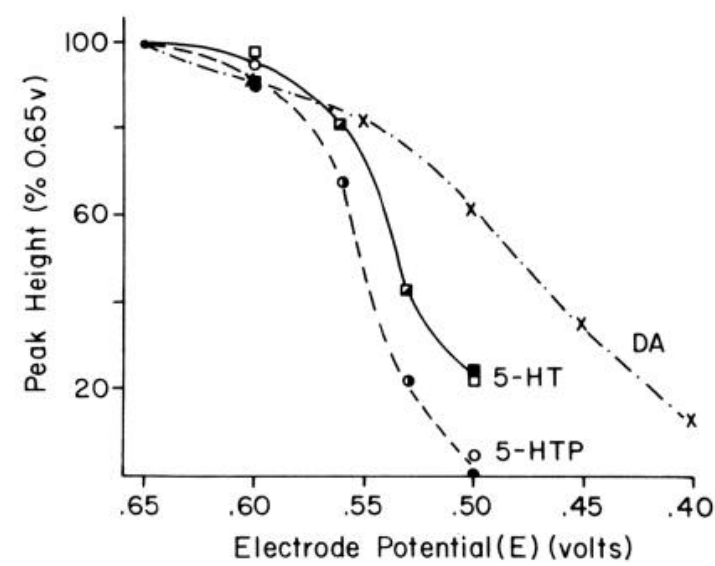

Figure 2. Voltammograms for putative 5-HTP $(\bigcirc)$ and 5HT ( $\square$ ) from chick retina obtained by repetitive injection of the same volume of extract while varying the potential of the working electrode. The solid symbols and that for dopamine $(D A)$ represent results obtained with the authentic compounds. 


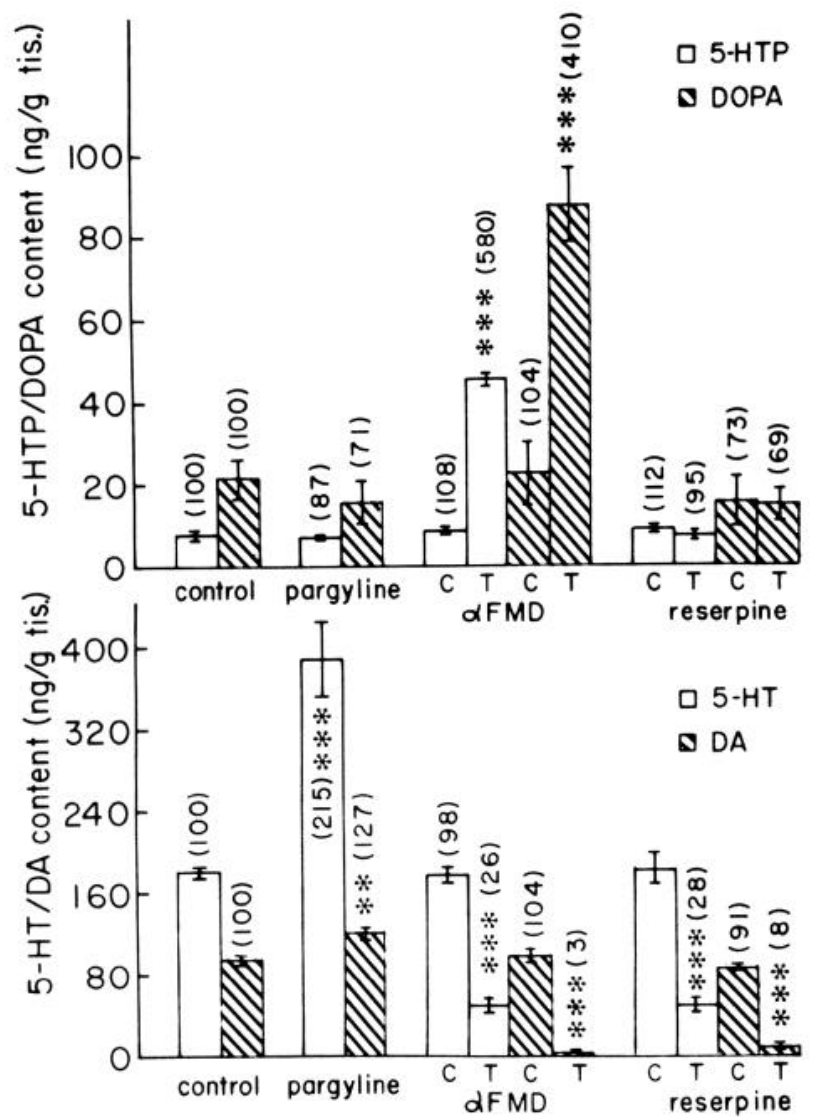

Figure 3. The effects of pargyline $(100 \mathrm{mg} / \mathrm{kg}$, i.p., $5 \mathrm{hr})$, reserpine ( $5 \mu \mathrm{g}$, i.vit., $24 \mathrm{hr}$ ), and $\alpha$-FMD ( $50 \mathrm{nmol}$, i.vit., $5 \mathrm{hr}$ ) on the retinal content of 5-HTP, 5-HT, DOPA, and dopamine $(D A)$ in 12-day-old light-adapted chicks. Results are the mean $( \pm$ SEM) of data from five animals in each treatment group. $C$, Untreated eye; $T$, treated eye. Results that are significantly different from control animal values by the Student's $t$ test are indicated as follows: $*, p<0.05 ; * *, p<0.01 ; * * *, p<0.0005$. Figures in parentheses are the value expressed as a percentage of the control animal value.

(MAO) by systemic administration of pargyline raised 5HT levels in the retina 2 -fold in $4 \mathrm{hr}$, while there was only a $30 \%$ increase in dopamine content over the same period. Both of these increases were statistically significant although this treatment did not affect the levels of precursor amino acids markedly. Intravitreal injection of $50 \mathrm{nmol}$ of $\alpha$-FMD into chick eyes irreversibly inhibits L-AAAD in $2 \mathrm{hr}$ (Parkinson et al., 1981) and prevents de novo synthesis of aromatic amines, such as 5-HT and dopamine. Five hours after this treatment, dopamine levels were at the limits of sensitivity of the assay with only $3 \%$ of the untreated levels remaining and the 5-HT content also had been reduced significantly. At the same time, both of the precursor amino acids were elevated significantly in the treated eye to 6- and 4-fold of the control values for 5-HTP and DOPA, respectively. An intravitreal injection of 1 (data not shown) or $5 \mu \mathrm{g}$ of reserpine reduced the levels of dopamine and 5-HT to 8 and $28 \%$, respectively, of the untreated eye in $24 \mathrm{hr}$ (Fig. $3)$. A higher dose of reserpine $(50 \mu \mathrm{g})$ injected into one eye caused apparent behavioral depression in the chicks which adopted the characteristic "head-down, eyes closed-shivering posture" of reserpine-treated animals. This dose reduced the 5-HT level to $60 \%$ of the contralateral eye after $24 \mathrm{hr}$, but compared to control animals, the levels of the untreated eye had been reduced by $50 \%$. Dopamine had been affected more severely by this dose, the levels in the untreated and treated eye having been reduced to 18 and $6 \%$ of control values, respectively.

Investigation of the synthesis of 5-HT by chick retina. We were unable to detect any in vitro tryptophan hydroxylase activity from chick retina by a method involving organic extraction of 5-HTP followed by quantitation with HPLC-ECD, although enzyme activity in chick midbrain was easily detectable (D. Parkinson and R. R. Rando, unpublished results). However, after intravitreal injection of $5 \mu \mathrm{Ci}$ of $\mathrm{L}-\left[\mathrm{G}-{ }^{3} \mathrm{H}\right]$ tryptophan/eye $(6.8 \mathrm{Ci} /$ mmol) to animals that had been pretreated with pargyline $(100 \mathrm{mg} / \mathrm{kg}$, i.p., $3 \mathrm{hr})$, significant amounts of radioactivity which co-eluted with 5-HT were measurable in four out of six retinae after $3 \mathrm{hr}$ and in five out of six retinae after $6 \mathrm{hr}$. The data from one such experiment is shown in Figure 4. The recording of absorbance at 254 nm shows that 5-HTP, 5-HT, and tryptophan were readily separated. 5-HIAA eluted 2 min after 5 -HTP but was removed by the extraction procedure. The animals had been pretreated with an MAO inhibitor so that acidic metabolites were not likely to have been formed. Tryptamine had a retention time of about 100 min under these conditions and so did not interfere. The mean data for one such experiment is shown in Figure $4 B$. The retinal extract still contained $\left[{ }^{3} \mathrm{H}\right]$ tryptophan $6 \mathrm{hr}$ after injection,

(A)

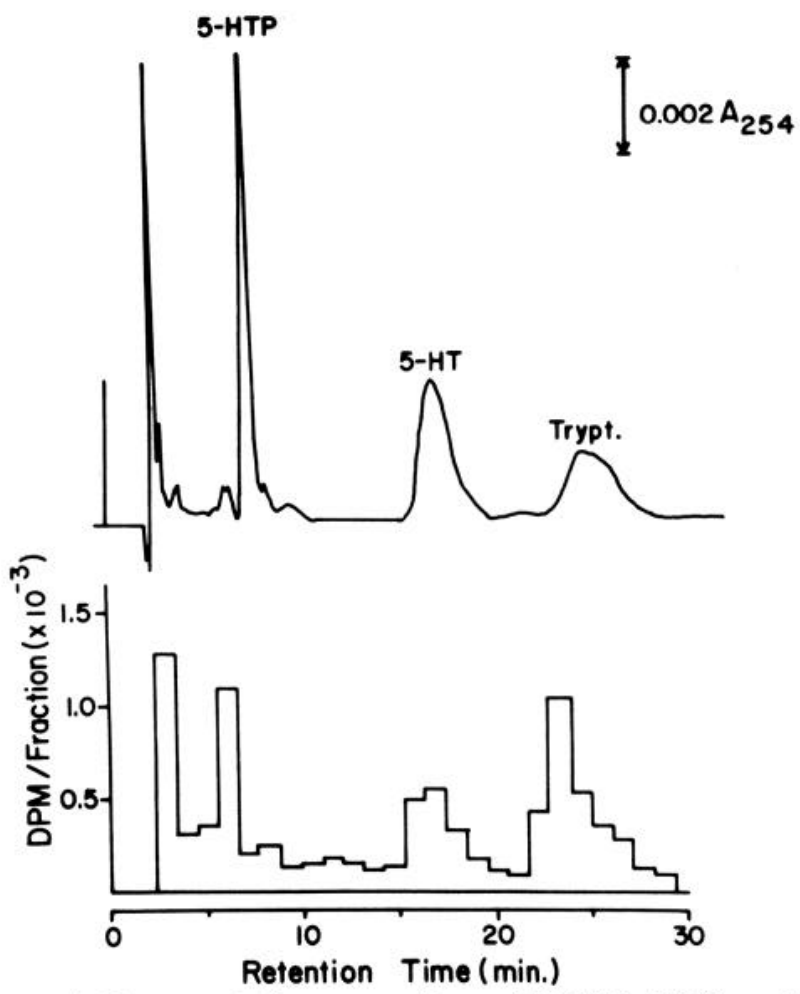

Figure 4. Representative separation of 5-HTP, 5-HT, and tryptophan (Trypt.) by ion pair reverse phase HPLC. $A$, Absorbance profile at $254 \mathrm{~nm} ; B$, separation of ${ }^{3} \mathrm{H}$-labeled metabolites after injection of $5 \mu \mathrm{Ci}$ (i.vit., $6 \mathrm{hr}$ ) of $\mathrm{L}-\left[{ }^{3} \mathrm{H}\right]$ tryptophan. 
but significant amounts of $5-\left[{ }^{3} \mathrm{H}\right] \mathrm{HT}$ had been synthesized. The sharp peak of radioactivity eluting at $6 \mathrm{~min}$ was found consistently, but it is not possible to say whether this is $5-\left[{ }^{3} \mathrm{H}\right] \mathrm{HTP}$ which has had its retention time reduced by some contaminant in the extract. After intravenous injection of $\left[{ }^{3} \mathrm{H}\right]$ tryptophan $(10 \mu \mathrm{Ci}$ /animal, wing vein), no radioactivity could be found in the retinal extracts after $3 \mathrm{hr}$.

Significant amounts of L-AAAD activity could be measured with DOPA as substrate in chick retina. The enzyme activity was $46.6 \mathrm{nmol}$ of dopamine formed $/ \mathrm{hr} / \mathrm{mg}$ of protein which was similar to that which we have obtained by measuring the release of ${ }^{14} \mathrm{CO}_{2}$ from L-[1${ }^{14}$ C]DOPA (D. Parkinson and R. R. Rando, unpublished results). With 5-HTP as the substrate, the activity was approximately 10 -fold lower at $3.6 \mathrm{nmol}$ of 5 -HT formed/ $\mathrm{hr} / \mathrm{mg}$ of protein. Both of these activities were inhibited totally by prior incubation with $5 \times 10^{-5} \mathrm{M}(S)-\alpha$-FMD for $30 \mathrm{~min}$ at $37^{\circ} \mathrm{C}$.

The effects of light on the synthesis and turnover of 5$H T$. Chicks that had been adapted to normal room light for $48 \mathrm{hr}$ had $70 \%$ higher levels of retinal 5 -HT than animals kept for the same time in total darkness (Table II). The levels of 5-HIAA in chick retina were low and approached the limits of sensitivity of the assay. However, there appeared to be a $50 \%$ higher 5-HIAA content in the light-adapted animals although this difference was only just significant.

An attempt to evaluate the effect of light adaptation on 5-HT turnover was made by following the decline in retinal content after blockade of synthesis with $\alpha$-FMD. Three hours after administration of a sufficient dose of $\alpha$-FMD to totally inactivate L-AAAD, the 5-HT content had fallen to $32.6 \pm 3.2 \%$ of the untreated eye in lightadapted animals, while the retinae of animals in total darkness had significantly lower basal levels of 5-HT and $49.4 \pm 6.1 \%$ of this was left $3 \mathrm{hr}$ after synthesis had been stopped (Fig. 5). The proportion of 5-HT left in the darkadapted animals was significantly greater $(p<0.05)$ than that in light-adapted chicks. The effects of light on 5HTP appeared to be the reverse. Thus, the basal levels of 5-HTP were higher in dark-adapted retinae and also increased to a greater proportion after $\alpha$-FMD compared to light-adapted retinae (Fig. 5).

\section{Discussion}

Ehinger and co-workers (Ehinger and Floren, 1976, 1978; Floren, 1979a) have been able to show that, in the

TABLE II

Retinal content of 5-HT and 5-HIAA in light-and dark-adapted chicks

The data are the mean $( \pm$ SEM) from five animals that had been adapted to normal room light or total darkness for $48 \mathrm{hr}$.

\begin{tabular}{|c|c|c|}
\hline & \multicolumn{2}{|c|}{ Tissue Content } \\
\hline & 5-HT & 5-HIAA \\
\hline & \multicolumn{2}{|c|}{ ng/gm tissue } \\
\hline Light & $119.4 \pm 15.6$ & $8.75 \pm 0.85$ \\
\hline Dark & $70.3 \pm 11.6^{a}$ & $5.89 \pm 1.07^{b}$ \\
\hline
\end{tabular}

\footnotetext{
${ }^{a} p<0.01$ by the Student's $t$ test.
}

${ }^{b} p<0.05$ by the Student's $t$ test.

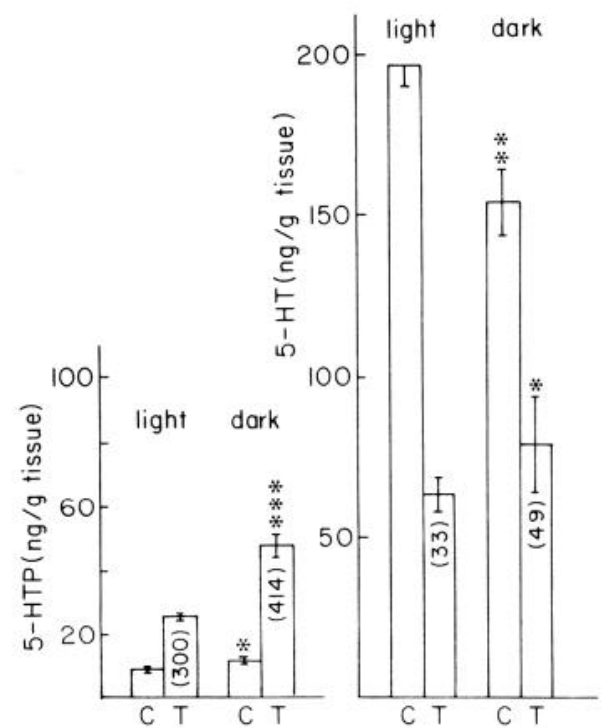

Figure 5. The effect of $\alpha$-FMD (50 nmol, i.vit., $3 \mathrm{hr}$ ) on the 5-HTP and 5-HT levels in the retinae of light- and dark-adapted chicks. Animals were adapted to total darkness or normal fluorescent room light for $48 \mathrm{hr}$ before the experiment. The results are the mean $( \pm \mathrm{SEM})$ of the data from six animals. Statistical significance between light and dark absolute untreated values and for $\alpha$-FMD treated values expressed as a percentage of the untreated control (figures in parentheses) were determined by Student's $t$ test and are indicated as follows: $*, p<0.05 ; * *, p<0.01 ; * * *, p<0.0005$. $C$, Untreated eye; $I$, treated eye.

retina of rabbit, cat, goldfish, pigeon, and chicken, there is an active transport mechanism capable of accumulating exogenous indoleamine. This active uptake process has properties similar to those found in the central nervous system and, in the rabbit retina, it appears to be distinct from the active uptake process for dopamine (Floren, 1979b). Rabbit retina appears to contain only dopaminergic neurons which can be demonstrated by the Falck-Hillarp fluorescence technique (Haggendal and Malmfors, 1965) although the indoleamine-accumulating neurons can be visualized in some species after taking up exogenous indoleamine (Ehinger and Floren, 1976; Floren, 1979a). The lack of any toxic effects from $p$-chloroamphetamine on the indoleamine-accumulating cells (Floren, 1979b) further argues against the presence of retinal tryptaminergic neurons in rabbit and it seems likely that the small amount of 5-HT $(\sim 20 \mathrm{ng} / \mathrm{gm}$ of tissue) present in this tissue is derived from platelets (Floren and Hansson, 1980).

Floren and Hansson (1980) have suggested that the endogenous indoleamine in chick retina may not be 5HT, since the cells containing it cannot be visualized readily by the histochemical fluorescence methods. The chromatographic and electrochemical data strongly suggest that the compounds that we were able to measure in chick retina were, in fact, 5-HTP and 5-HT. Many alternative candidates, such as 5-methoxytryptamine (Ponzio and Jonsson, 1979), 5,6-dihydroxytryptamine, melatonin, $N, N$-dimethyltryptamine, and tryptamine (W. Jacobs, personal communication), can be excluded because they have different electrochemical properties than 5-HT. $N$ - 
Acetyl-5-HT is an indoleamine with oxidation characteristic similar to $5-\mathrm{HT}$, but they are well resolved by the HPLC (retention time of 53 and 13 min, respectively, with $\mathrm{C5}$ ion pair). The indoleamine in retina appears to be a ready substrate for MAO. This enzyme will not easily oxidize arylalkylamines with $N$ substituents larger than $\mathrm{CH}_{3}$ (Blaschko, 1974). These data strongly suggest that the indoleamine present in chick retinae is 5-HT.

Hauschild and Laties (1973) were able to visualize an indoleamine contained in amacrine cells in chick embryo retina from 16 days of incubation to their latest time point of 21 days. These cells could be distinguished from catecholamine-containing cells by their fluorescent characteristics and response to pharmacological treatments. Our evidence suggests that 5-HT is the transmitter in these cells. However, Floren (1979b) could not see with certainty any such cells in embryo, newborn, or older chickens without the administration of exogenous indoleamine.

With a ninhydrin-based fluorescence assay, Suzuki and co-workers (Suzuki et al., 1977) found amounts of 5-HT in chick retina similar to those that we have been able to measure in light-adapted chicks. They also found that systemic treatment with reserpine lowered the retinal content of 5-HT and that pargyline raised it. A tryptophan load did not increase 5-HT levels, suggesting that the synthetic mechanism may be saturated with tryptophan in retina in contrast to the brain (Suzuki et al., 1975). However, a systemic treatment also would affect any extraretinal sources of 5-HT and so might explain the observed results. Our observation that local administration of reserpine into the eye markedly lowers 5-HT in the treated but not contralateral eye implies that this amine is stored in the retina. The observation that the small but measurable amount of 5-HTP is elevated markedly after inhibition of retinal L-AAAD suggests that the 5 -HT is synthesized locally. After this acute block of synthesis, 5-HT levels are reduced, implying a significant amount of turnover of this amine during $5 \mathrm{hr}$.

Neuronal 5-HT is synthesized from L-tryptophan by the sequential action of tryptophan hydroxylase and $\mathrm{L}$ AAAD. The latter enzyme also is involved in the synthesis of catecholamines, but the former has been used as a marker for tryptaminergic neurons (McGeer and McGeer, 1973a). We could not measure any tryptophan hydroxylase in chick retinal homogenates. However, in vivo, the chick retina is able to synthesize $5-\left[{ }^{3} \mathrm{H}\right] \mathrm{H}$ 'T from $\mathrm{L}-\left[{ }^{3} \mathrm{H}\right]$ tryptophan even after inhibition of MAO when such conversion is known to be reduced (Hamon et al., 1972; Macon et al., 1971). Our failure to demonstrate tryptophan hydroxylase in vitro may have been due to an assay that was not sufficiently sensitive or to the instability of the enzyme (Gal, 1974; McGeer et al., 1963).

Finally, we sought evidence that stimulation of the retina (i.e., by light) in some way changed the turnover of its stores of 5-HT as an indication of a neurotransmitter role for this indoleamine. The levels of 5-HIAA that we could measure in chick retinae were lower than have been reported for chick brain (Suzuki et al., 1975) and bovine retina (Thomas and Redburn, 1979) as were the levels of 5-HT (Bourne, 1965; Eiduson, 1971; Pscheidt and Tammie, 1966; Suzuki et al., 1975). The low levels of 5-HIAA may result from a particularly efficient organic acid transport system as the retinal contents of the acidic metabolites of dopamine are lower than most brain areas (D. Parkinson and R. R. Rando, manuscript in preparation). However, retinal 5-HIAA is increased by $50 \%$ in light- compared to dark-adapted animals, suggesting that tryptaminergic neurons are stimulated by light. After total inhibition of L-AAAD, the rate of decline of retinal 5 -HT in a light or dark environment could be used as a measure of its neuronal use and, at the same time, the rate of increase of 5-HTP levels would give an index of the rate of synthesis. The latter is based upon the assumption that, like its role in catecholamine synthesis, L-AAAD is not rate limiting for the conversion of tryptophan to 5-HT. Our results and those of Christenson et al. (1970) suggest that, under the same assay conditions, 5-HTP is only decarboxylated at one-tenth the rate of DOPA. However, there is in vivo evidence to suggest that L-AAAD is not the rate-limiting enzyme in 5-HT synthesis (Grahame-Smith, 1974). We have found consistently that basal 5-HT levels are higher in light- than dark-adapted retinae. The turnover of 5-HT was also higher in the retina of light-adapted chicks as indicated by the greater proportion of the amine that was lost over $3 \mathrm{hr}$. Curiously, however, the rate of increase of 5-HTP after inhibition of L-AAAD appeared to be significantly greater in dark-adapted chicks. If this were a true representation of the in vivo rate of tryptophan hydroxylase activity, then the basal levels of 5-HT should be highest in dark-adapted retinae. Inhibition of $\mathrm{L}$-AAAD also affects dopamine metabolism and, in normal room light, there is a greater than $95 \%$ depletion of dopamine and a 6- to 8-fold increase in L-DOPA content of chick retina within $4 \mathrm{hr}$ (Parkinson et al., 1981). There is evidence that high concentrations of L-DOPA inhibit tryptophan hydroxylase in vitro and in vivo (McGeer et al., 1963; McGeer and McGeer, 1973b) and, conversely, that dopamine receptor blockade reduces 5-HT levels (Burki et al., 1975). If these mechanisms are operative in the retina, then they might explain the discrepancy between the apparent in vivo rate of synthesis and the steady state levels of 5-HT in light- and dark-adapted chicks. Light adaptation increases dopamine synthesis and turnover in the retina of rat (Iuvone et al., 1978) and chick (D. Parkinson and R. R. Rando, manuscript in preparation). In the brain, stimulation of dopamine receptors by apomorphine increases the turnover of central 5-HT in rats (Grabowska, 1976; Scheel-Kruger and Hasselager, 1974). Therefore, if dopaminergic neurons are presynaptic to tryptaminergic neurons in chick retina, then the arguments advanced above to explain the anomalous rates of synthesis of 5-HTP after inhibition of L-AAAD under light and dark adaptation also could be applied to effects on 5-HT turnover. That is, depletion of dopamine would impair neuronal function which would reduce its effect to stimulate turnover of 5-HT. Therefore, it is possible that the turnover of 5-HT in light-adapted chick retina is greater than we can estimate from our results. Clearly, interpretation of this data is not possible without further work to clarify any relationship between dopaminergic and tryptaminergic neurons.

In conclusion, we have presented evidence to suggest that 5 -HT may be a neurotransmitter in chick retina since $(a)$ it is stored locally, $(b)$ it appears to be synthe- 
sized in the retina, and $(c)$ its rate of turnover may be related to neuronal function in the retina. We cannot say from our data whether 5-HT is the neurotransmitter per se or an intermediate for some other compound. However, the data show that the 5-HT present is probably highly localized since its storage is reserpine sensitive. As there appears to be more of this indoleamine than dopamine in 12-day chick retina, the reasons why some workers could not demonstrate its localization by the histochemical fluorescence method remain to be determined. More work is required to derive the relationship of dopamine and other retinal transmitters, such as GABA, to the indoleamine-containing cells in the chick retina.

\section{References}

Blaschko, H. (1974) The natural history of amine oxidases. Rev. Physiol. Biochem. Pharmacol. 70: 83-148.

Bourne, B. B. (1965) Metabolism of amines in the brain of the chick during embryonic development. Life Sci. 4: 583-591.

Burki, H. R., W. Ruch, and H. Asper (1975) Effects of clozapine, thioridazine, perlapine and haloperidol on the metabolism of the biogenic amines in the brain of the rat. Psychopharmacology (Berlin) 41: 27-33.

Christenson, J. G., W. Dairman, and S. Udenfriend (1970) Preparation and properties of a homogenous aromatic Lamino acid decarboxylase from hog kidney. Arch. Biochem. Biophys. 141: 356-367.

Ehinger, B. (1976) Biogenic amines as transmitters in the retina. In Transmitters in the Visual Process, S. L. Bonting, ed., pp. 145-163, Pergamon Press, Oxford.

Ehinger, B., and I. Floren (1976) Indoleamine accumulating neurons in the retina of rabbit, cat and goldfish. Cell Tissue Res. 175: 37-48.

Ehinger, B., and I. Floren (1978) Chemical removal of indoleamine accumulating terminals in rabbit and goldfish retina. Exp. Eye Res. 26: 321-328.

Eiduson, S. (1971) Biogenic amines in the developing brain. In Cellular Aspects of Neuronal Growth and Differentiation, U.C.L.A. Forum in Medical Science, D. C. Pease, ed., No. 14, pp. 391-414, University of California Press, Berkeley.

Floren, I. (1979a) Arguments against 5-hydroxytryptamine as neurotransmitter in the rabbit retina. J. Neural Transm. 46: $1-15$.

Floren, I. (1979b) Indoleamine accumulating neurons of the retina of pigeon and chick: A comparison with dopaminergic neurons. Acta Ophthalmol. (Copenh.) 57: 198-210.

Floren, I., and H. C. Hansson (1980) Investigations into whether 5 -hydroxytryptamine is a neurotransmitter in the retina of rabbit and chicken. Invest. Ophthalmol. Vis. Sci. 19: 117-125.

Gal, E. M. (1974) Tryptophan-5-hydroxylase: Function and control. Adv. Biochem. Psychopharmacol. 18: 1-11.

Grabowska, M. (1976) The involvement of serotonin in the mechanism of central action of apomorphine. Pol. J. Pharmacol. Pharm. 28: 389-394.

Grahame-Smith, D. G. (1974) How important is the synthesis of brain-5-hydroxytryptamine in the physiological control of its central function. Adv. Biochem. Psychopharmacol. 10: 8391.

Haggendal, J., and T. Malmfors (1965) Identification and cellular localization of the catecholamines in the retina and choroid of the rabbit. Acta Physiol. Scand. 64: 58-66.
Hamon, M., S. Bourgoin, T. Moro-Gaudry, and T. Glowinski (1972) End product inhibition of serotonin synthesis in the rat striatum. Nature New Biol. 237: 184-187.

Hauschild, D. C., and A. M. Laties (1973) An indoleamine containing cell in chick retina. Invest. Ophthalmol. Vis. Sci. 12: $537-540$

Hefti, F. (1979) A simple sensitive method for measuring 3,4dihydroxyphenylacetic acid and homovanillic acid in rat brain tissue using high pressure liquid chromatography with electrochemical detection. Life Sci. 25: 775-782.

Iuvone, P. M., C. L. Galli, C. K. Garrison-Gund, and N. H. Neff (1978) Light stimulates tyrosine hydroxylase activity and dopamine synthesis in retinal amacrine neurons. Science 202: 901-902.

Kollonitsch, J., A. A. Patchett, S. Marburg, A. L. Maycock, L. M. Perkins, G. A. Doldouras, D. E. Duggan, and S. D. Aster (1978) Selective inhibitors of the biosynthesis of aminergic neurotransmitters. Nature 274: 906-908.

Laduron, P., and F. Belpaire (1968) A rapid assay and partial purification of DOPA decarboxylase. Anal. Biochem. 26: 210218.

Macon, J. B., L. Sokoloff, and J. Glowinski (1971) Feedback control of rat brain 5-hydroxytryptamine synthesis. J. Neurochem. 18: 323-331.

McGeer, P. L., and E. G. McGeer (1973a) Neurotransmitter synthetic enzymes. Prog. Neurobiol. 2: 71-117.

McGeer, P. L., and E. G. McGeer (1973b) Metabolic Inhibitors, p. 45, Academic Press, New York.

McGeer, P. L., E. G. McGeer, and J. A. Wada (1963) Central aromatic amine levels and behaviour. II. Serotonin and catecholamine levels in various cat brain areas following administration of psychoactive drugs as amine precursors. Arch. Neurol. 9: 81-89.

Parkinson, D., R. Baughman, R. H. Masland, and R. R. Rando (1981) Dopamine metabolism following irreversible inactivation of aromatic amino acid decarboxylase in retina. J. Neurosci. 1: 1205-1210

Ponzio, F., and G. Jonsson (1979) A rapid and simple method for the determination of picogram levels of serotonin in brain tissue using liquid chromatography with electrochemical detection. J. Neurochem. 32: 129-132.

Pscheidt, S., and H. S. Tammie (1966) Brain amines and brain weights in growing chicks: Some normal values and effects of feeding excess dietary L-phenylalanine. Biochem. Pharmacol. 15: $1629-1639$.

Rando, R. R. (1974) The chemistry and enzymology of $K_{\text {cat }}$ inhibitors. Science 185: 320-324.

Scheel-Kruger, J., and E. Hasselager (1974) Studies of various amphetamines, apomorphine and clonidine on body temperature and brain 5-HT metabolism in rats. Psychopharmacology (Berlin) 36: 189-202.

Shellenberger, M. K., and J. H. Gordon (1971) A rapid, simplified procedure for the simultaneous assay of norepinephrine, dopamine and 5-hydroxytryptamine for discrete brain areas. Anal. Biochem. 39: 356-372.

Suzuki, O., F. Nagase, and K. Yagi (1975) Tryptophan metabolism in developing chick brain. Brain Res. 93: 455-462.

Suzuki, O., E. Noguchi, S. Miyake, and K. Yagi (1977) Occurrence of 5-HT in chick retina. Experientia 33: 927-928.

Thomas, T. N., and D. A. Redburn (1979) 5-Hydroxytryptamine-a neurotransmitter of bovine retina. Exp. Eye Res. 28: 55-61.

Udenfriend, S., E. Titus, and H. Weissbach (1955) The identification of 5HIAA in normal urine and a method for its analysis. J. Biol. Chem. 216: 499-505. 